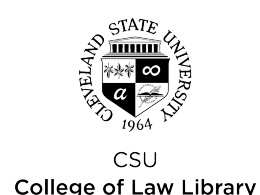

Cleveland State University

College of Law Library

\title{
EngagedScholarship@CSU
}

Winter 2008

\section{Developing Internal Consistency in Writing Assignments by Involving Students in Problem Drafting}

Karin M. Mika

Cleveland State University, k.mika@csuohio.edu

Follow this and additional works at: https://engagedscholarship.csuohio.edu/fac_articles

Part of the Legal Writing and Research Commons

How does access to this work benefit you? Let us know!

\section{Original Citation}

Karin Mika, Developing Internal Consistency in Writing Assignments by Involving Students in Problem Drafting, 16 Perspectives: Teaching Legal Research and Writing 122 (Winter 2008)

This Article is brought to you for free and open access by the Faculty Scholarship at EngagedScholarship@CSU. It has been accepted for inclusion in Law Faculty Articles and Essays by an authorized administrator of EngagedScholarship@CSU. For more information, please contact research.services@law.csuohio.edu. 


\section{Developing Internal Consistency in Writing Assignments by Involving Students in Problem Drafting}

\section{${ }^{66}$ Introductions}

\section{should always}

reflect an

organization of

what is to follow, and what follows

should reflect the

order set out in

the introduction."

\section{By Karin Mika}

Karin Mika is Professor of Legal Writing at ClevelandMarshall College of Law in Ohio.

One of the greatest challenges first-year students seem to face is understanding the concept of internal consistency within a document. That is, many students, at least initially, do not seem to comprehend the relationship among portions of a memo or any type of legal writing. All "good" writing involves an element of consistency. Introductions should always reflect an organization of what is to follow, and what follows should reflect the order set out in the introduction. The title of a paper should bear some relationship to the content of the paper, and any headings should accurately reflect what is contained in the material that follows.

The organization of any type of legal writing is similar. With respect to a memorandum of law specifically, the facts in a fact-specific issue should be reflected in a statement of facts. The "relevant" facts should be reflected in the factual application whether in the introductory paragraph to the memo or afterward. There should also be a relationship between the relevant facts and the facts from cases that are chosen to be analogized.

There are many examples of the incorrect and internally inconsistent ways that documents are initially written during the first year of law school. All legal writing professors are familiar with the student who states that the resolution to an issue involves applying a three-part test, and then goes on to introduce cases that resolved the issue set forth based on a totality of the circumstances test. Other examples include suggesting that the paper will follow a chronological order, then providing no such order, or suggesting that several cases define the law, then setting out only one.
More likely than not, the inconsistency of the introductory paragraph and the body of the document makes for such a muddle of information that the reader cannot possibly understand any later application of the law. Additionally, because the introductory paragraph is inconsistent with what follows, the writer (student) loses the ability to engage in any type of self-critique and often meanders off on a trail of related information that does not fall into any appropriate legal (or even compositional) structure.

Other examples of consistency problems specifically related to a memorandum of law include the student setting out an issue that bears no relationship to the discussion that follows. A recent example from my own experience relates to an assigned issue that posed the question whether it would be negligence per se if a hotel owner failed to install smoke detectors as mandated by state law and guests were injured during a subsequent fire.

In the memo in question, the student set out the appropriate issue (which was assigned as written) and parroted the facts pretty much in the way that I had constructed the scenario; however, the memo went on to define the law in terms of general negligence principles. Some of the cases used did involve fires at hotels, but not in relation to whether a state law mandated that smoke detectors be installed. None of the cases involved negligence per se. Essentially, the memo set out the elements of negligence, and then went through cases in which individuals were deemed negligent. Very little specific comparison of facts was made, and the end product did not address the initial issue posed.

When the student came in for a conference regarding the memo, I found it difficult explaining that he did not answer the issue posed. Given that the memo did, at points, discuss a hotel owner's negligence in 
situations involving fire, and analogized negligence cases to a negligence situation, the student did not understand why I believed that the initial question was not answered. When reexamining the facts the student had written, it became clear that the problem in consistency had arisen because the student had subtly shifted the focus of the facts in the statement of facts from the lack of smoke detectors to the fire itself.

In many respects, this was my fault. Given that the issue posed a question about a statute and smoke detectors, I read my fact scenario as clearly focusing on negligence per se. The student read it as focusing on negligence. The slight nuance of this shift in how he related the facts changed the entire focal point of the memo and became the basis for his answering a much different question than was posed.

The situation is demonstrative of a problem that many first-year and even upper-level students have-understanding why a document is not internally consistent when the cases chosen and analyzed involve part of the same subject matter of the issue presented and have some factual relation to the facts provided.

Recently, I tried a new strategy regarding teaching internal consistency and avoiding this problem.

During one of my classes, I divided the students into groups. For each group, I assigned a very factspecific issue statement, for example, "Whether a public utility is liable for negligence when a child is injured after the child climbs up a utility pole by way of a ladder left out by a utility company worker who was planning to return to the site the following day."

Based on issues like these, the students then drafted their own fact situations, which presumably incorporated facts that raised the relevant issues. After the fact situations were drafted, we critiqued them and then discussed what could or should have been included so that the fact situation corresponded to the issue. We then discussed what cases we would be looking for in order to ensure that the research corresponded to both the issue presented and the fact situation that was drafted.
The next step was similar, but it involved assigning the students issues that were much more general in nature such as, "Under what circumstances would a utility company be liable for an injury sustained by a child who has climbed up a utility pole?" I again asked the groups to draft fact situations related to the issue. However, this time, the students had much more discretion in writing fact situations that would reflect how the child was able to climb up the utility pole, and how the child was injured.

After the students completed this portion of the exercise, the class again discussed what research was necessary for the individual fact situations, and how these cases might differ from the previous cases that had been discussed. For instance, in a fact situation involving a ladder that was left out in anticipation of work the next day (the first hypothetical), the student would presumably focus on research involving cases in which a multiday project was anticipated, and what safety mechanisms were customary in the profession in such an instance. The student would also research cases in which the employee perhaps did not adhere to his or her company's own safety standards and would likely research cases where work equipment posed an attractive nuisance to children given the location of the equipment.

If, however, the student modified the original hypothetical to reflect that the child climbed up the pole by using a ladder that was accidentally left behind (and not part of a multiday project), the research path would change. In that instance, the student would be researching cases in which equipment was accidentally left out. The student would also need to focus on the nature of the resulting accident and injury. Additionally, despite the fact that the issue focuses on the liability of a utility company, it would be prudent for the researcher to look into cases where ladders, specifically, were left out, and read any commentary the courts may have on the dangerousness of a ladder left in the open in any venue. The research need not focus on industry standards and whether those standards were violated by the placement of the ladder.
${ }^{66}$ After the fact situations were drafted, we critiqued them and then discussed what could or should have been included so that the fact situation corresponded to the issue." " 
${ }^{6}$ By seeing how research results differ when changing the facts slightly, the student gets an idea of what must be considered when answering a broader issue."
In both situations, there would be a body of research that is overlapping, but depending on the specificity of the facts, the research universe would change slightly. By seeing how research results differ when changing the facts slightly, the student gets an idea of what must be considered when answering a broader issue. For example, "When is the utility company responsible for the injury to a child who falls after climbing up a utility pole?"

In both instances above, we have assumed the existence of a ladder left out by a utility worker. Considering the specificity of the ladder-and indeed drafting the situation themselves-leads students to understand the broader questions such as "What must be left out for there to be liability?" The student should be able to formulate the answer to the general question because, by examining the nuances in specific situations, the student should be able to identify the distinction between injury caused by a lack of appropriate protocol of the company (or breached protocol by the employee) and injury caused by an accidental act of the employee.

Following this class exercise in which we changed facts to reflect the specific nature of the issue or changed the issue to reflect the specific nature of the facts, I assigned a research project that incorporated this exercise. Each student was given a general issue and, after doing some preliminary research, the student drafted his or her own fact situation and modified the issue accordingly. The student then re-researched the modified issue prior to writing a memo. The entire process was memorialized in a log to be submitted along with the final draft.
As I had hoped, the memos I received had much more internal consistency than memos for which I had assigned the hypothetical fact situation. It seems as though the students' integration into the process of actually drafting what they were to research enabled them to better focus on what would be the central themes of their work. Although in the "real world," attorneys are not able to change the fact situation to reflect their research, the involvement of the writer in determining what facts are to be included in a statement of facts appears to enable a writer to better focus on what law needs to be researched. Certainly attorneys must extract fact situations from files of documents; thus they are performing the same type of task required in this exercise.

Although many first-year legal writing assignments include a limited universe in which the professor sets out the legally significant facts, this might, in fact, be adding to the problems students face in making an entire document consistent with respect to issue, facts, and law. Providing students with the opportunity to become more involved in the drafting process may, in fact, be more beneficial and enable the students to internalize a concept that is often difficult to get across.

(c) 2008 Karin Mika 